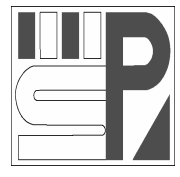

Science Press
Journal of Arid Land

2012, 4(3): 241-250

doi: 10.3724/SP.J.1227.2012.00241

jal.xjegi.com; www.chinasciencejournal.com

.

\title{
The impact of land use change on soil organic carbon and labile organic carbon stocks in the Longzhong re- gion of Loess Plateau
}

\author{
LiHua ZHANG $^{1 *}$, ZhongKui XIE ${ }^{1}$, RuiFeng ZHAO ${ }^{2}$, YaJun WANG ${ }^{1}$ \\ ${ }^{1}$ Gaolan Experiment Station for Ecology and Agriculture Research, Cold and Arid Regions Environmental and Engineering \\ Research Institute, Chinese Academy of Sciences, Lanzhou 730000, China; \\ ${ }^{2}$ College of Geography and Environment Science, Northwest Normal University, Lanzhou 730070, China
}

\begin{abstract}
Land use change (LUC) is widely recognized as one of the most important driving forces of global carbon cycles. The soil organic carbon (SOC) and labile organic carbon (LOC) stores were investigated at arable land (AL), artificial grassland (AG), artificial woodland (AW), abandoned arable land (AAL) and desert steppe (DS) in the Longzhong region of the Loess Plateau in Northwest China. The results showed that conversions from DS to $A L, A L$ to $A G$ and $A L$ to $A A L$ led to an increase in SOC content, while the conversion from $D S$ to $A W$ led to a decline. The differences in SOC content were significant between DS and AW at the 20-40 cm depth and between AL and AG at the $0-10 \mathrm{~cm}$ depth. The SOC stock in DS at the $0-100 \mathrm{~cm}$ depth was $39.4 \mathrm{t} / \mathrm{hm}^{2}$, increased by $28.48 \%$ after cultivation and decreased by $19.12 \%$ after conversion to AW. The SOC stocks increased by $2.11 \%$ from AL to AG and $5.10 \%$ from AL to AAL. The LOC stocks changed by a larger magnitude than the SOC stocks, which suggests that it is a more sensitive index of carbon dynamics under a short-term LUC. The LOC stocks increased at 0-20 cm and $0-100 \mathrm{~cm}$ depths from DS to AW, which is opposite to that observed for SOC. The proportion of LOC to SOC ranged from 0.14 to 0.20 at the $0-20 \mathrm{~cm}$ depth for all the five land use types, indicating low SOC dynamics. The allocation proportion of LOC increased for four types of LUC conversion, and the change in magnitude was largest for DS to AW (40.91\%). The afforestation, abandonment and forage planting on arable land led to sequestration of SOC; the carbon was lost initially after afforestation. However, the carbon sink effect after abandonment may not be sustainable in the study area.
\end{abstract}

Keywords: carbon sequestration; labile organic carbon; land use; cultivation; abandonment; Loess Plateau

The carbon pool in soils is approximately twice as much as that in the atmosphere (IPCC, 2007). The atmospheric $\mathrm{CO}_{2}$ concentration is influenced by the balance between soil organic carbon (SOC) inputs and outputs (Lützow et al., 2006). Land use change (LUC), one of the dominant components of global change, is estimated to be the second largest source of human-induced greenhouse gas emissions (1.5 Pg C/a) after fossil fuel combustion (5.3 Pg C/a) (IPCC, 2007). Changes in SOC upon LUC may occur due to changes in the rates of accumulation, turnover and decomposition of SOC (Li et al., 2010; Poeplau et al., 2011). Thus, improved understanding for land use impacts on the terrestrial carbon balance is a necessary part of global efforts to mitigate climate change.

The SOC fractions differ in their response and sensitivity to LUC. Active soil organic carbon is easily and directly used by organisms. It is active and most sensitive to physical and chemical disturbances (Purakayastha et al., 2007). These SOC fractions are also important for nutrient cycle. Labile organic carbon (LOC), a fraction of active soil organic carbon, can be measured easily using $\mathrm{KMnO}_{4}$ oxidation and can serve as a sensitive indicator for the dynamic of SOC due to

Received 2011-10-31; accepted 2012-03-25

"Corresponding author: LiHua ZHANG (E-mail: zhangzhuang80@126.com) 
land use and management change (Wu et al., 2004; Su et al., 2009).

The Loess Plateau covers an area of some 640,000 $\mathrm{km}^{2}$ in the upper and middle reaches of the Yellow River. Loess is a highly erosion-prone soil; in fact, the soil in this region has been called "the most highly erodible soil on earth" (Yang and Shao, 2000). The Loess Plateau and its dusty soil cover almost all of Shanxi and Shaanxi provinces, as well as parts of Gansu province, the Ningxia Hui autonomous region, and the Inner Mongolia autonomous region.

Since the 1950s, substantial efforts have been made to control soil erosion and restore vegetation in the hilly areas of the Loess Plateau by the Chinese government, including extensive tree planting, integrated soil erosion controls and the "Grain-for-Green" project. There is a diversity of land use types. The effects of land use on soil carbon storage have become the focus of research (Wu et al., 2004; Chen et al., 2007; Liu et al., 2010). Longzhong is located in the middle of Gansu province and the west of the Loess Plateau, where the natural environment is harshest, the economy most undeveloped and vegetation restoration most difficult (Zhang and Huang, 2002). Reports on soil carbon sequestration related to land use are, however, seldom available.

In this study, SOC and LOC storage were determined for each land use type: arable land (AL), artificial grassland ( $\mathrm{AG})$, abandoned arable land (AAL), artificial woodland (AW) and desert steppe (DS). The effects of land use on the SOC pool were analyzed to provide a theoretical basis to rational land use and conservation in the region.

\section{Materials and methods}

\subsection{Study area}

The experimental site is at the Gaolan Experiment Station for Ecology and Agriculture Research, Cold and Arid Regions Environmental and Engineering Research Institute, Chinese Academy of Sciences (Fig. 1). The station is located in the northwest of the Loess Plateau (Gaolan county, Lanzhou, Gansu province; $\left.36^{\circ} 13^{\prime} \mathrm{N}, 103^{\circ} 47^{\prime} \mathrm{E}\right)$ at an altitude of approximately $1,780 \mathrm{~m}$. The climate is semi-arid and drought-prone: the mean annual precipitation is about $263 \mathrm{~mm}$, with nearly $70 \%$ falling between May and September; the mean annual temperature is $8.4^{\circ} \mathrm{C}$, with a maximum

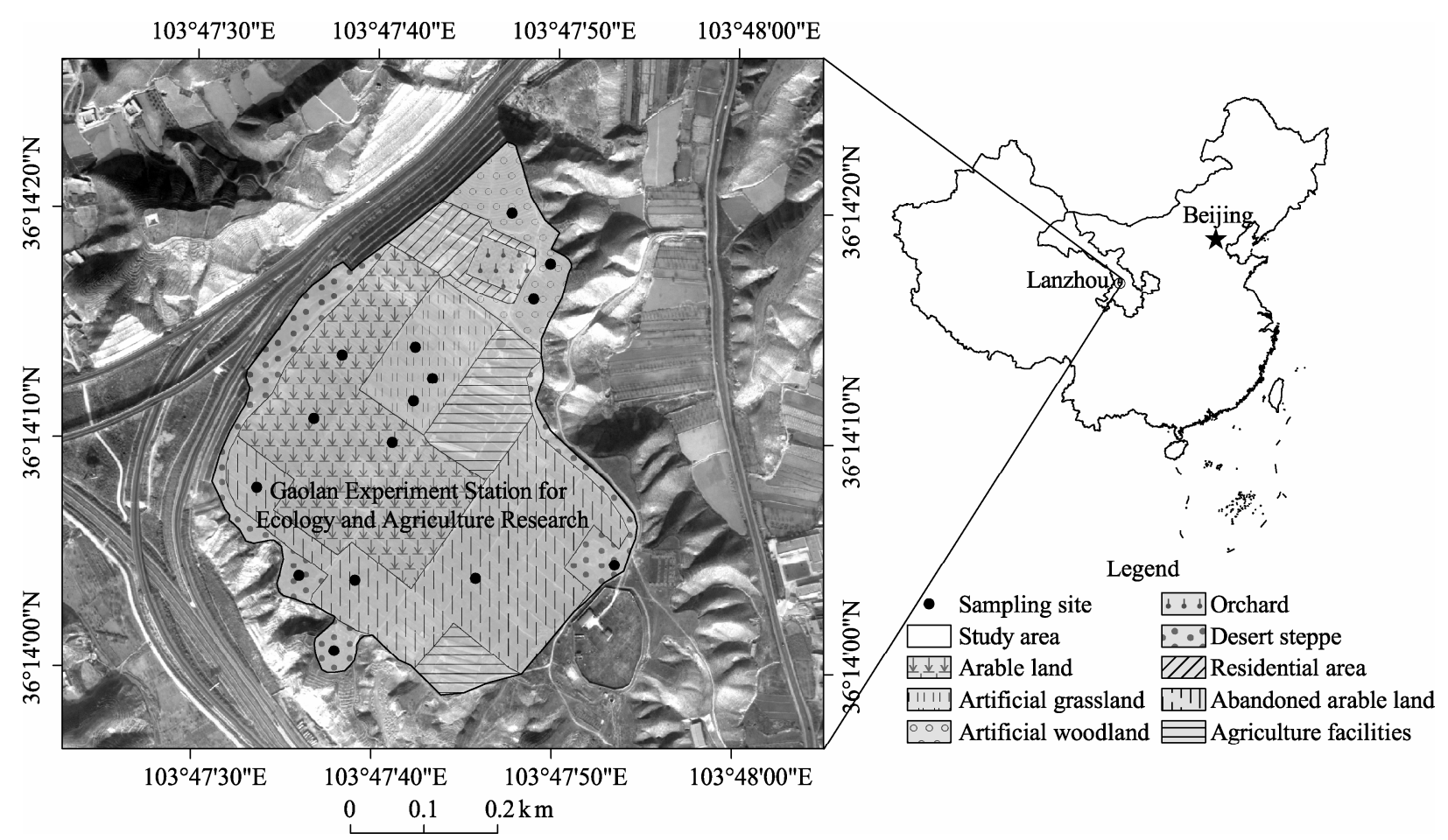

Fig. 1 Location of the study area and sample scheme of different land uses 
monthly mean value of $20.7^{\circ} \mathrm{C}$ (July) and a minimum monthly mean value of $-9.1^{\circ} \mathrm{C}$ (January); the average annual pan evaporation is $1,786 \mathrm{~mm}$. The vegetation is desert steppe. The soil is a silt loam of loess origin, which belongs to the Sierozem soil classifications according to Chinese Soil Taxonomy.

The AL in this study has a cultivation history of over 50 years and was planted with maize (Zea mays L.) continuously from 2004 to the present, and with wheat and vegetable previous to 2004. The fields were plowed before sowing in spring, and after harvest the maize residue was left in field. Experimental fields were irrigated three times per year following fertilizer application of di-ammonium phosphate (200 $\left.\mathrm{kg} / \mathrm{hm}^{2}\right)$ and urea $\left(100 \mathrm{~kg} / \mathrm{hm}^{2}\right)$. Organic manure was applied every 6 years at approximately $8,000 \mathrm{~kg} / \mathrm{hm}^{2}$. The AG had been under continuous alfalfa production since 2001, being irrigated once or twice per year. The alfalfa was harvested (cut near the soil surface) one or two times per year. Crops such as wheat and potato were grown previous to the alfalfa. Vegetation of the AW was oriental arborvitae (Platycladus orientalis L.), which was planted in 2003, following pear trees, which had been planted in 1992 . The oriental arborvitae was $1.5 \mathrm{~m}$ apart within rows and $2 \mathrm{~m}$ apart between rows and trees were irrigated at their bases three to four times per year. The AAL was left abandoned for six years and had been planted with maize and vegetable previously. The species were Artemisia frigida L., Artemisia sacrorum L. and Chenopodium album L. The coverage was about $30 \%$. Approximately $25 \%$ of the surface area of the DS was covered by Reaumuria soongorica L. and Stipa breviflora L., which were dominant, and other less prevalent species, such as Peganum harmala L., Astragalus capillipes L., Cleistogenes mitica L. and Setaria viridis L.

\subsection{Soil sampling and analysis}

In May 2010, we took soil samples from three sites of each land use type by collecting five cores $(5 \mathrm{~cm}$ in diameter) from six depths (0-10, 10-20, 20-40, 40-60, 60-80 and $80-100 \mathrm{~cm}$ ) in a zigzag sampling pattern. The five cores at each depth were mixed to form a composite sample. Soil cores were measured for soil bulk density in a stainless steel cylinder of $100 \mathrm{~cm}^{3}$. In the laboratory, the bulked samples were air-dried and passed through a $2-\mathrm{mm}$ sieve to remove coarse roots and easily-detected plant litter.

Soil particle size distribution was determined using the laser detection technique on a Malvern Mastersizer 2000 (Malvern Instruments Ltd., Malvern, UK). The particle size was classified by the American Soil Texture Taxonomy, and sand was in the range of 50-1,000 $\mu \mathrm{m}$, silt $2-50 \mu \mathrm{m}$ and clay $<2 \mu \mathrm{m}$. Soil organic carbon (SOC) was measured by the $\mathrm{K}_{2} \mathrm{Cr}_{2} \mathrm{O}_{7}-$ $\mathrm{H}_{2} \mathrm{SO}_{4}$ oxidation method of Walkey and Black (Nelson and Sommers, 1982). Total nitrogen (total N) was measured by the micro-Kjeldahl procedure (ISSCAS, 1978). Labile organic carbon (LOC) was measured by the $\mathrm{KMnO}_{4}(0.333 \mathrm{~mol} / \mathrm{L})$ oxidation method (Su et al., 2009). For an individual profile with $\mathrm{k}$ layers, the following equation was used to calculate the storage of organic carbon at each layer of the soil profile:

$$
S O C=h \times \rho \times C .
$$

Where, SOC is the soil organic carbon storage $\left(\mathrm{t} / \mathrm{hm}^{2}\right)$, $h$ the thickness of this layer $(\mathrm{cm}), \rho$ the bulk density $\left(\mathrm{g} / \mathrm{cm}^{3}\right)$, and $C$ the proportion of organic carbon $(\%)$.

Labile organic carbon in soil was calculated using an equation similar to the above.

\subsection{Statistical analyses}

All data were analyzed using SPSS software. Multiple comparisons and analyses of variance (ANOVA) were used to determine the significance of differences in SOC and LOC at each depth among land use types.

\section{Results}

\subsection{Effects of LUC on SOC content}

Conversion from DS to AL led to a slight increase in SOC content at the $0-100 \mathrm{~cm}$ depth (Table 1). The SOC content decreased as land use changed from DS to AW, except at the $80-100 \mathrm{~cm}$ depth where it increased, and was significantly different at the 20-40 $\mathrm{cm}$ depth between the two land use types. Conversion from $\mathrm{AL}$ to $\mathrm{AG}$ led to an increase in SOC content at 0-10 and 60-100 cm depths, with a small decline at the middle of the profile. A trend to increased SOC content was observed in the transition of AL to AAL, but it was not statistically significant. 
Table 1 SOC content for various land use types

\begin{tabular}{cccccc}
\hline \multirow{2}{*}{ Depth $(\mathrm{cm})$} & \multicolumn{5}{c}{ Land use type } \\
\cline { 2 - 5 } & $\mathrm{DS}(\mathrm{g} / \mathrm{kg})$ & $\mathrm{AL}(\mathrm{g} / \mathrm{kg})$ & $\mathrm{AG}(\mathrm{g} / \mathrm{kg})$ & $\mathrm{AAL}(\mathrm{g} / \mathrm{kg})$ & $\mathrm{AW}(\mathrm{g} / \mathrm{kg})$ \\
\hline $0-10$ & $5.7 \pm 0.6^{\mathrm{ACa}}$ & $6.1 \pm 0.2^{\mathrm{ADa}}$ & $8.0 \pm 0.3^{\mathrm{Ba}}$ & $7.3 \pm 0.5^{\mathrm{BDa}}$ & $4.4 \pm 0.5^{\mathrm{Ca}}$ \\
$10-20$ & $4.8 \pm 0.8^{\mathrm{ABab}}$ & $5.6 \pm 0.1^{\mathrm{Aa}}$ & $5.6 \pm 0.4^{\mathrm{Ab}}$ & $6.1 \pm 0.2^{\mathrm{Ab}}$ & $3.5 \pm 0.6^{\mathrm{Bac}}$ \\
$20-40$ & $4.2 \pm 0.5^{\mathrm{Abd}}$ & $4.6 \pm 0.3^{\mathrm{Ab}}$ & $4.0 \pm 0.5^{\mathrm{Abc}}$ & $5.0 \pm 0.5^{\mathrm{Ac}}$ & $2.4 \pm 0.6^{\mathrm{Bbc}}$ \\
$40-60$ & $2.9 \pm 0.2^{\mathrm{Acd}}$ & $3.9 \pm 0.4^{\mathrm{Abd}}$ & $3.8 \pm 0.8^{\mathrm{Abc}}$ & $4.0 \pm 0.3^{\mathrm{Ace}}$ & $2.4 \pm 0.6^{\mathrm{Abc}}$ \\
$60-80$ & $2.6 \pm 0.2^{\mathrm{Ac}}$ & $3.1 \pm 0.3^{\mathrm{Acd}}$ & $3.6 \pm 1.2^{\mathrm{Abc}}$ & $3.2 \pm 0.3^{\mathrm{Ade}}$ & $2.1 \pm 0.6^{\mathrm{Abc}}$ \\
$80-100$ & $2.1 \pm 0.1^{\mathrm{Ac}}$ & $2.8 \pm 0.3^{\mathrm{Ac}}$ & $3.0 \pm 1.1^{\mathrm{Ac}}$ & $2.9 \pm 0.2^{\mathrm{Ad}}$ & $2.2 \pm 0.4^{\mathrm{Abc}}$ \\
Mean & $3.7 \pm 0.3^{\mathrm{AB}}$ & $4.3 \pm 0.2^{\mathrm{A}}$ & $4.7 \pm 0.6^{\mathrm{A}}$ & $4.7 \pm 0.3^{\mathrm{A}}$ & $2.8 \pm 0.5^{\mathrm{B}}$ \\
\hline
\end{tabular}

Note: Different capital letters in the same row and different small letters in the same column indicate significant difference at $P<0.05$. Means \pm standard errors were calculated from three sites of the same land use type. DS, desert steppe; AL, arable land; AG, artificial grassland; AAL, abandoned arable land; AW, artificial woodland.

On average, over the $0-100 \mathrm{~cm}$ soil profile, the SOC content was in the order: AAL $>\mathrm{AG}>\mathrm{AL}>\mathrm{DS}$ $>$ AW (Table 1). The SOC content was significantly higher in $\mathrm{AL}, \mathrm{AG}$ and $\mathrm{AAL}$ than in $\mathrm{AW}(P<0.05)$ at the $0-40 \mathrm{~cm}$ depth, and was not significantly different among land use types $(P>0.05)$ at the $40-100 \mathrm{~cm}$ depth. The SOC content decreased with increasing soil depth in the $0-100 \mathrm{~cm}$ soil profile for all the land use types, with a small amplitude at the $40-100 \mathrm{~cm}$ depth. The SOC content in the upper depths $(0-10$ and $10-20 \mathrm{~cm}$ ) differed from that in the subsoil depths in all five land use types (Table 1).

Soil C/N ratio ranged from 6.4 to 8.6 (Fig. 2), and although not significant, the trend was to higher ratios in AAL, AL and AG than in DS and AW. The largest $\mathrm{C} / \mathrm{N}$ ratio was with the topsoil layer. Total $\mathrm{N}$ was significantly and positively correlated with SOC content for all land use types $(P<0.001)$.

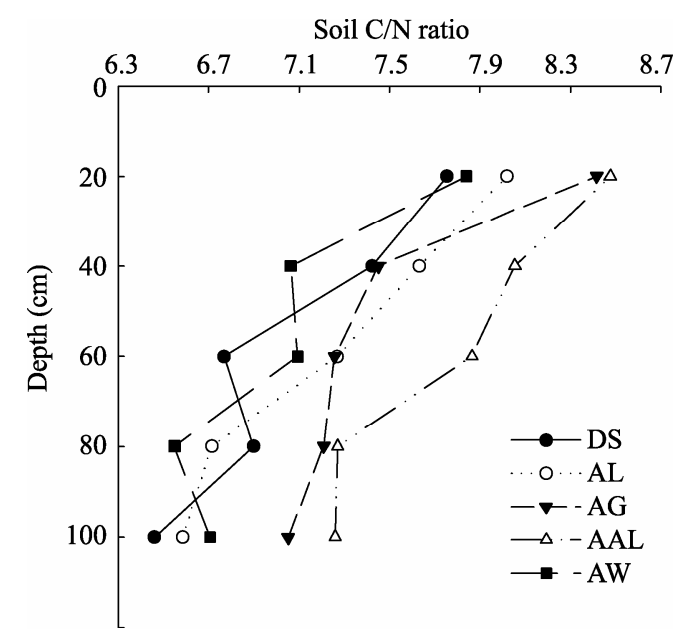

Fig. 2 Soil $\mathrm{C} / \mathrm{N}$ ratio for each land use type

\subsection{Effects of LUC on SOC storage}

At the $0-100 \mathrm{~cm}$ depth, the SOC storage in DS was
$39.4 \mathrm{t} / \mathrm{hm}^{2}$, increased to $50.6 \mathrm{t} / \mathrm{hm}^{2}$ after cultivation by an amplitude of $28.5 \%$ and decreased to $31.9 \mathrm{t} / \mathrm{hm}^{2}$ after conversion to AW by an amplitude of $19.1 \%$ (Fig. 3). The SOC storage reached $51.7 \mathrm{t} / \mathrm{hm}^{2}$, with an increase of $2.1 \%$ for the transition from $\mathrm{AL}$ to $\mathrm{AG}$ and $5.1 \%$ after abandonment of $\mathrm{AL}$. When the $\mathrm{AL}$ was converted to AG and was abandoned, the SOC storage at the $0-20 \mathrm{~cm}$ depth increased by $22.6 \%$. The SOC storage at the $0-20 \mathrm{~cm}$ depth decreased by $22.2 \%$ after conversion from DS to AW, and increased by $13.2 \%$ after cultivation.

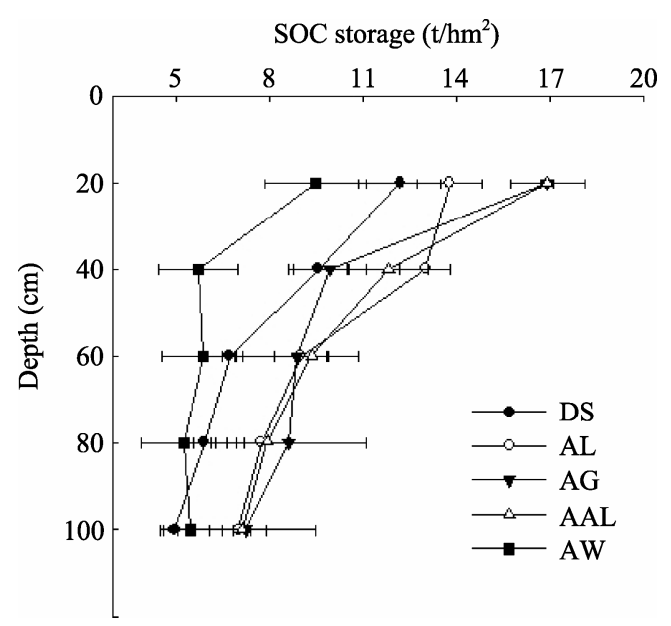

Fig. 3 SOC storages for each land use type. Data are the means \pm standard error of 3 observations $(n=3)$.

The order of SOC storage magnitude was consistent with that of the SOC content over the $0-100 \mathrm{~cm}$ profile among all land use types. The SOC storage of AL was higher at the $20-40 \mathrm{~cm}$ depth, which might be related to increasing bulk density due to tillage. The deep, dense roots of alfalfa might have contributed to the high SOC storage at the $60-100 \mathrm{~cm}$ depth, which was greater than in any other land use type (Fig. 3). 
The amplitude of SOC storage change was higher at the $0-20$ and $20-40 \mathrm{~cm}$ depths than at deeper soil depths for four land use conversions (Fig. 4). But it was also high at the 40-100 cm depth after conversion from DS to AL. The largest change in SOC storage $\left(3.4 \mathrm{t} / \mathrm{hm}^{2}\right)$ occurred at the $20-40 \mathrm{~cm}$ depth in the change from DS to AL, while there was little difference among other soil depths (approximately $1-2 \mathrm{t} / \mathrm{hm}^{2}$ ).

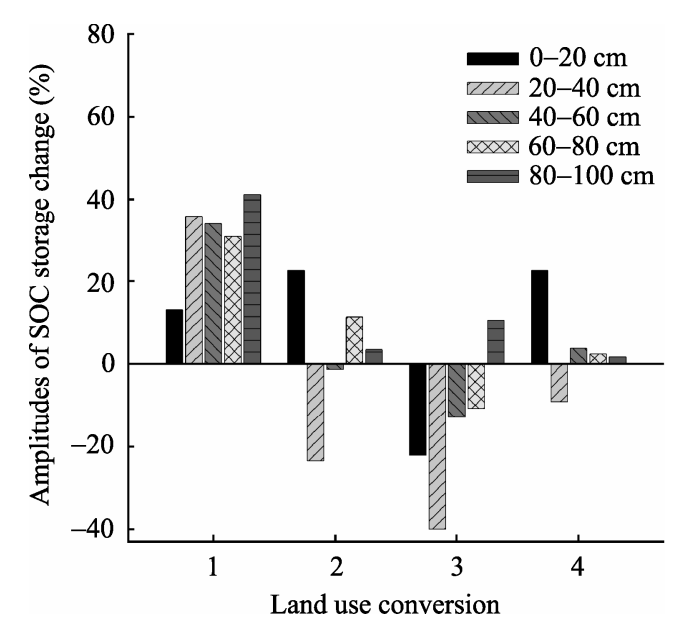

Fig. 4 Amplitudes of SOC storage change for different modes of land use conversion. 1 , conversion from $D S$ to $A L ; 2$, conversion from $A L$ to $A G ; 3$, conversion from $D S$ to $A W ; 4$, conversion from AL to AAL.

\subsection{Effects of LUC on LOC}

The LOC storage in the $0-100 \mathrm{~cm}$ soil profile was 5.2 $\mathrm{t} / \mathrm{hm}^{2}$ in DS, increased to $6.94 \mathrm{t} / \mathrm{hm}^{2}$ by an amplitude of $34.5 \%$ after cultivation and by $2.7 \%$ in the transition to AW. The LOC storage in the $0-100 \mathrm{~cm}$ soil profile increased by $6.2 \%$, reaching $7.4 \mathrm{t} / \mathrm{hm}^{2}$ following the conversion of $\mathrm{AL}$ to $\mathrm{AG}$, and increased by $11.9 \%$ after $\mathrm{AL}$ was abandoned. The order of LOC storage was $\mathrm{AAL}>\mathrm{AG}>\mathrm{AL}>\mathrm{AW}>\mathrm{DS}$. LOC storage was larger in AW than in DS, while SOC storage was larger in DS than in AW (Fig. 5). LOC storage decreased with the increase of soil depth.

The amplitude of LOC storage change was higher than that of SOC storage (Figs. 4, 6), which might indicate that LOC was more sensitive than SOC in response to LUC. Particularly, the LOC storage increased by over $80 \%$ at the $80-100 \mathrm{~cm}$ depth, which differed from the $10.7 \%$ increase in SOC storage at the 80-100 cm depth following the conversion of DS to AW. The LOC storage increased by $55.4 \%$ at the

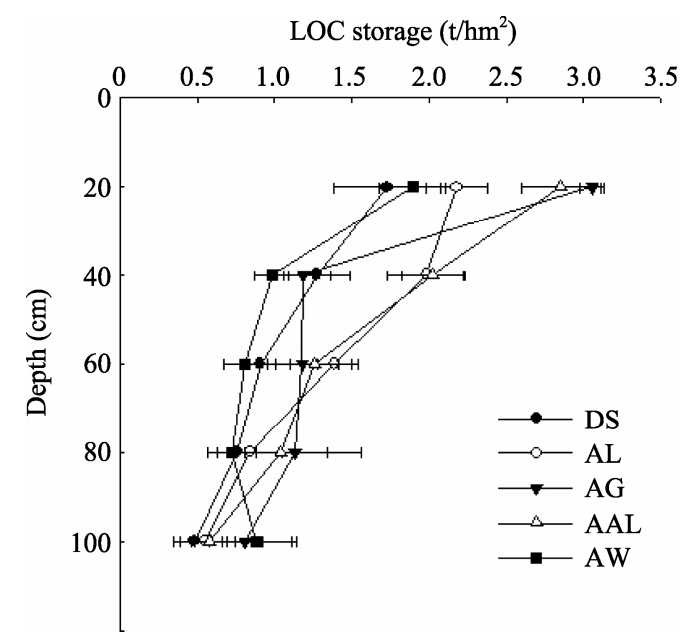

Fig. 5 LOC storage for each land use type. Data are the means \pm standard error of 3 observations $(n=3)$.

$20-40 \mathrm{~cm}$ depth and $52.5 \%$ at the $40-60 \mathrm{~cm}$ depth, higher than the increase in SOC storage $(35.9 \%$ and $34.0 \%$, respectively) after DS was cultivated. Additionally, the LOC storage increased at the $60-100 \mathrm{~cm}$ depth in the conversion from AL to AG.

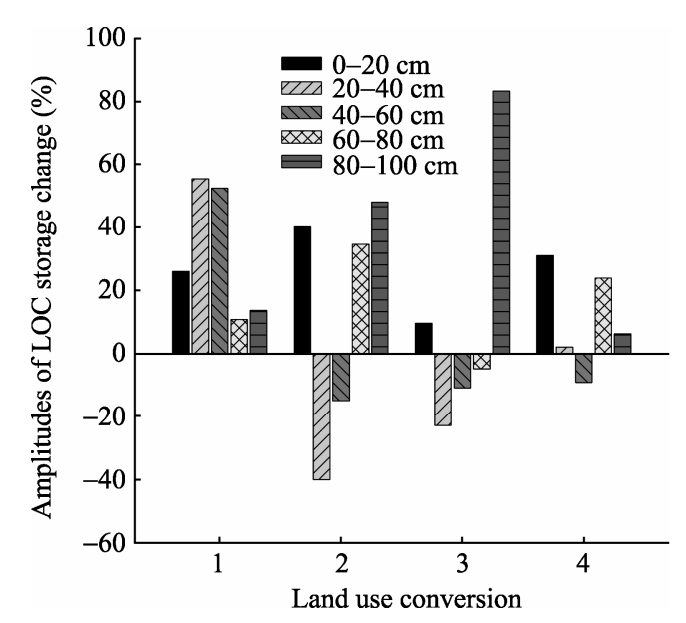

Fig. 6 Amplitudes of LOC storage change for different modes of land use conversion. 1 , conversion from $\mathrm{DS}$ to $\mathrm{AL} ; 2$, conversion from $A L$ to $A G ; 3$, conversion from $D S$ to $A W ; 4$, conversion from AL to AAL.

The allocation proportion of LOC is the ratio of LOC content to SOC content. For the soil sample at the $0-20 \mathrm{~cm}$ depth, the allocation proportion of LOC in DS was 0.14 , increased by $11.2 \%$ after cultivation and by the largest degree (40.9\%) when converted to AW (Fig. 7). The allocation proportion of LOC increased by $14.2 \%$ and $6.8 \%$ from $\mathrm{AL}$ to $\mathrm{AG}$ and $\mathrm{AG}$ to AAL, respectively. 

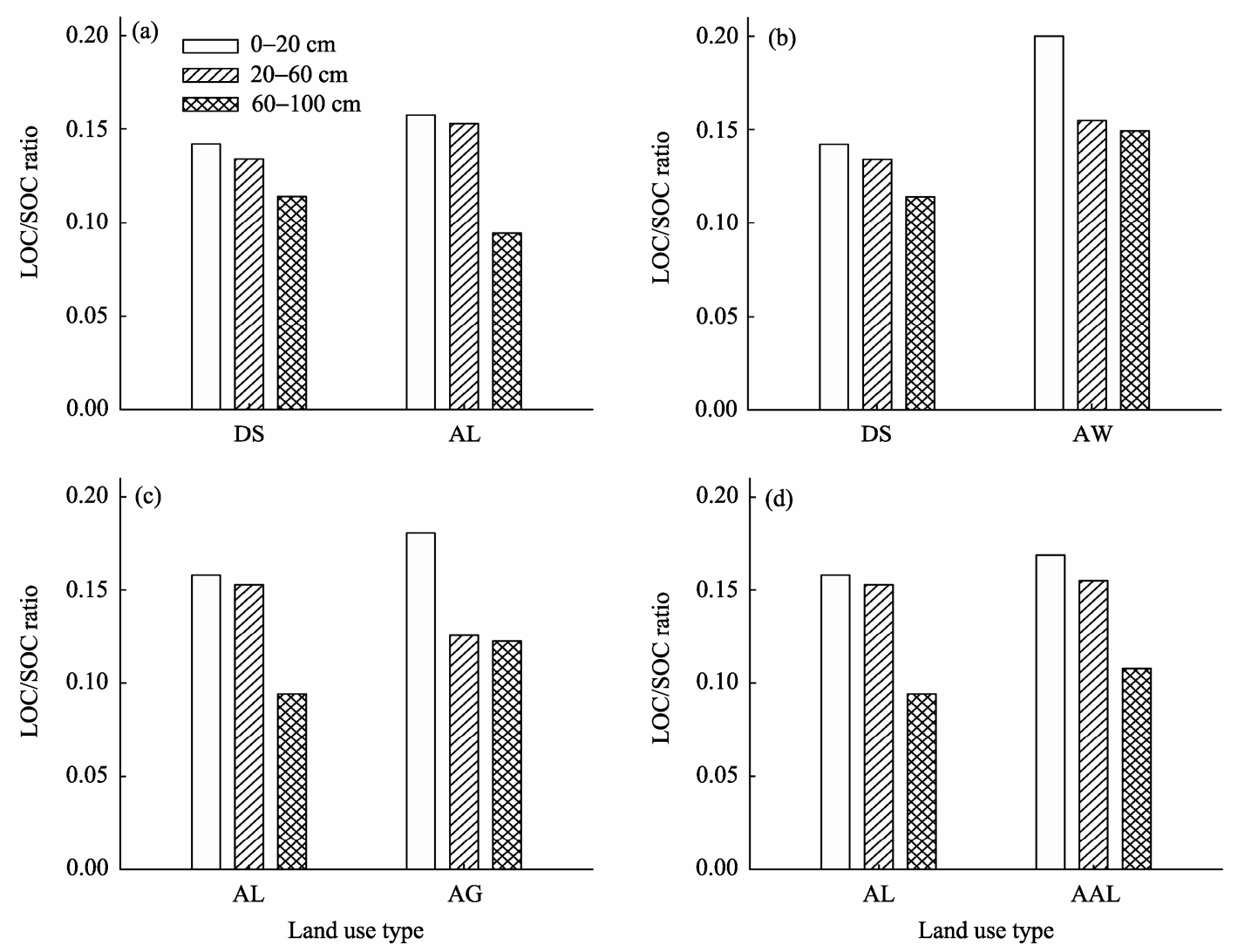

Fig. 7 Allocation proportion change of LOC after land use conversion

\section{Discussion}

\subsection{Impacts of LUC on SOC content and storage}

In the study area, except for significant differences in SOC content at the $0-10 \mathrm{~cm}$ depth in the conversion from $\mathrm{AL}$ to $\mathrm{AG}$ and at the $20-40 \mathrm{~cm}$ depth in the conversion from $\mathrm{DS}$ to $\mathrm{AW}$, the SOC content did not change significantly following LUC. This was probably related to the short period of time since the LUC occurred, the similar soil physical and chemical properties and the litter trait, as well as management among the land use types. Soil $\mathrm{pH}$ was in the range of 8.9-9.2 and soil bulk density was from 1.15 to 1.24 for the five land use types.

In this study, the conversion of DS to AL led to increases in SOC content and storage. This result was not consistent with the study by Liu et al. (2010), who reported that the accumulation of SOC was greater in natural grassland than in arable land in the southern Loess Plateau. Wang et al. (2007) concluded that SOC content in woodland and grassland decreased after cultivation in the central Loess Plateau. The area in this study is located in the northwest of the Loess Plateau, with a temperate, semi-arid and drought-prone climate and mean annual precipitation of $263 \mathrm{~mm}$. The mean annual precipitation is $602 \mathrm{~mm}$ and $558 \mathrm{~mm}$ in the other two areas, respectively. The zonal vegetation is also different, desert steppe for our study and forests for the other two studies. At the south and centre of the Loess Plateau, there is more litter and root in forest and grassland soils than in arable land, and consequently SOC accumulates in forest and grassland soils more than in arable land. At the northwest of the Loess Plateau, vegetation coverage and vegetation biomass are low in desert steppe; dry branches and fallen leaves decompose slowly and accumulate at the soil surface, and carbon input into the soil is less than in forest and grassland. The SOC stock of the arable land might be higher than that of the desert steppe due to organic manure applications and the effect of crop residues. Luo et al. (2005) found that the nutrient status of soil was improved after conversion of desert 
to arable land in an arid region. The influence of conversion from natural vegetation to arable land on SOC differed among regions. It was concluded that cultivation of wetland at the Sanjiang Plain (Wang et al., 2009), reclamation of alpine meadow in Haibei (Li et al., 2006) and reclamation of grassland in a northern agro-pastoral ecotone (Liu et al., 2009) led to decreased SOC content as well as transition from native forest to arable land in mid-subtropical mountainous areas (Yang et al., 2009). Whereas, the SOC content in arable land was higher than that in a saline meadow or grassland of medium coverage in the middle of Heihe River (Zhang et al., 2009; Wang et al., 2011). In addition to the differences in climate, vegetation and soil type, the SOC content of irrigated soils increased after cultivation according to Wu et al. (2003). The study of Chen et al. (2008), which concluded that the dry field will be a large carbon sink under good management due to the reduction of slow organic carbon pool and an increase in the passive organic carbon pool from forest to dry farmland, supports our research result on the effect of LUC on SOC. Thus, the response of the carbon pool to LUC and its regional difference need to be examined.

In this paper, SOC stock in arable land increased after abandonment, which agrees with the results observed in the studies on land left abandoned for 20 years (Li et al., 2009; Wei et al., 2011) and 75 years (Guo et al., 2010) in the Loess Plateau, and for a century in southeastern Ontario, Canada (Foote and Grogan, 2010). Land abandonment for several decades also improved soil physical-chemical and microbiological properties in semi-arid regions (Guo et al., 2010; Zhu et al., 2010; Wang et al., 2011; Raiesi, 2012a, b). Consequently, the $\mathrm{C}$ sink after abandonment is correlated with the nutrient status of the soils. Nevertheless, it has been found that the herbage develops toward shrub in the middle and late stages of succession in other regions of the Loess Plateau ( $\mathrm{Du}$ et al., 2007; Zhu et al., 2010; Wang et al., 2011), and the increasing root to shoot ratio of the community would influence biomass accumulation and decomposition of soil organic matter (Du et al., 2007). Thus, in the desert steppe, the soil carbon sequestration potential may be restricted with soil degradation when vegetation regenerates to desert steppe after abandonment of ar- able land. The dynamics of plant and soil nutrients and chronosequences of abandoned farmland need to be investigated in the study area.

Conversion from AL to AG led to a significant increase of SOC content in this study, which is in accordance with the results of several studies (Guo and Gifford, 2002; Chen et al., 2007; Su et al., 2009) and is probably related to the input of more plant relicts into soil and the reduction of tillage operations (Wu et al., 2004). The higher SOC content at the 10-60 cm depth in AL compared with AG might be due to increasing carbon sequestration after long-term fertilizer application (Morari et al., 2006). Alfalfa has a strong taproot system, and its root can reach seven to nine meters (Guo et al., 2002), whereas annual crop roots are shallow. Thus, the SOC content at the $60-100 \mathrm{~cm}$ depth was higher in alfalfa grassland.

The SOC content and storage decreased in the transition from DS to AW, which agrees with the results of afforestation in meadow steppe (Liu et al., 2009) and in degraded sandy grassland ( $\mathrm{Hu}$ et al., 2007). Paul et al. (2002) summarized the results of forty three studies conducted in different regions and concluded that SOC content was usually lower in artificial woodland converted within less than ten years than in former land with other types of vegetation, declined slowly with increasing tree age, and would be higher than the former land after thirty years or longer time. Moreover, the main factors contributing to restoration of SOC after afforestation include previous land use, species of trees planted, soil clay content, preplanting disturbance and climatic zone (Laganière et al., 2010).

\subsection{Impacts of LUC on LOC storage}

The LOC in soil derived from litter decomposition, root secretion, hydrolysis of soil organic matter and soil microorganisms, as well as its metabolic production, plays an important role in maintaining soil fertility and indicating the change in SOC storage ( $\mathrm{Wu}$ et al., 2004). In our study, the trend for LOC storage change resembled that for the SOC storage after land use conversions, which suggested that the size of the LOC pool was mainly determined by the SOC pool (Rong et al., 2011). Matched application of organic manure and fertilizer efficiently increased the LOC content in $\mathrm{AL}(\mathrm{Xu}$ et al., 2006). Additionally, en- 
hanced soil water content due to irrigation had a positive influence on the formation of LOC. The difference in LOC between AG and AL resulted from much root secretion and litter owing to a larger biomass in grassland and less human disturbance. Jia et al. (2006) reported soil microbial carbon and LOC increased following abandonment, which was similar to the increase in LOC in AAL in our study. The higher LOC storage in AW than in DS resulted from higher litter quality and quantity (Wu et al., 2004; Laik et al., 2009). Furthermore, the larger change in the amplitude of LOC than in SOC might imply that the change in SOC mainly occurred in the active fraction during the short period after land use conversion.

The proportion of LOC to SOC content is used to reflect the stability of soil carbon, and a higher proportion means greater activity and lower stability of SOC (Zhu et al., 2006). In this study, the conversions between several land use types caused the increase in this proportion. Meanwhile, the proportion of LOC to SOC content at the $0-20 \mathrm{~cm}$ soil depth was in the range of $0.14-0.20$, lower than $0.28-0.44$ for different land use types in a dry, hot valley (Tang et al., 2010) and 0.45-0.52 in subtropical forests (Zhu et al., 2006). Thus, the activity of SOC was low and stable carbon was the main fraction in the study area. It was probably related to the fine soil texture in the study area. Poeplau et al. (2011) reported that a higher proportion of mineral and aggregate-bound SOC contributed to slower SOC dynamics in fine textured

\section{References}

Chen J Y, Sun B, Li Z P, et al. 2008. Pool size of soil organic carbon and dynamics under different land use. Journal of Soil and Water Conservation, 22(1): 91-96.

Chen L D, Gong J, Fu B J, et al. 2007. Effect of land use conversion on soil organic carbon sequestration in the loess hilly area, Loess Plateau of China. Ecological Research, 22: 641-648.

Du F, Liang Z S, Xu X X, et al. 2007. The community biomass of abandoned farm land and its effects on soil nutrition in the loess hilly region of northern Shanxi, China. Acta Ecologica Sinica, 27(5): 1673-1683.

Foote R L, Grogan P. 2010. Soil carbon accumulation during temperate forest succession on abandoned low productivity agricultural lands. Ecosystems, 13: 795-812. soils compared with sandy soils in which the particulate SOC is more abundant.

\section{Conclusions}

The conversion of DS to AL caused a soil carbon sink. The combined use of irrigation, fertilizers, manure and plant residues has obviously changed the carbon content at the $100-\mathrm{cm}$ depth in the last five decades. The abandonment and planting of forage on arable land led to sequestration of SOC, particularly in the topsoil layer. The afforestation on arable land had a negative effect on the SOC content at an early stage. After abandonment, however, the carbon sink is probably restricted under desert steppe conditions. Soil might degrade as vegetation regenerates to desert steppe during the secondary succession after abandonment. The carbon sequestration will be influenced by the degraded nutrient status of the soils. Thus, the carbon sink effect after abandonment may not be sustainable and might become a carbon source over time in the study area; however how long it would take is unknown.

\section{Acknowledgements}

This study was supported by the Foundation for Excellent Youth Scholars of Cold and Arid Regions Environmental and Engineering Research Institute, Chinese Academy of Sciences (Y084941) and the National Natural Science Foundation of China (41171027). The authors thank the editors and anonymous reviewers for their valuable comments on the manuscript.

Guo L B, Gifford R M. 2002. Soil carbon stocks and land use change: a meta analysis. Global Change Biology, 8: 345-360.

Guo M, Zheng F L, He W X, et al. 2010. Variation of vegetation diversity and its relationship with soil nutrient and enzyme activity in lands of different abandoned years in the loess hilly-gully region. Acta Pedologica Sinica, 47(5): 979-986.

Guo Z G, Zhang Z H, Xiao J Y, et al. 2002. Root system development ability of several alfalfa cultivars in the hilly and valley regions of Loess Plateau. Chinese Journal of Applied Ecology, 13(8): 1007-1012.

Hu Y L, Zeng D H, Fan Z P, et al. 2007. Effects of degraded sandy grassland afforestation on soil quality in semi-arid area of Northern China. Chinese Journal of Applied Ecology, 18(11): 2391-2397. 
Institute of Soil Sciences, Chinese Academy of Sciences (ISSCAS). 1978. Physical and Chemical Analysis Methods of Soils. Shanghai: Shanghai Science Technology Press, 7-15.

Intergovernmental Panel of Climate Change (IPCC), 2007. In: Solomon S, Qin D, Manning M, et al. IPCC Climate Change: the Physical Science Basis. Cambridge: Cambridge University Press, 996.

Jia G M, Fang X W, Liu B R, et al. 2006. Size and activity of microbial biomass in vegetation restoration of abandoned arable land in central region of Loess Plateau, China. Journal of Desert Research, 26 (4): 580-584.

Laganière J, Angers D A, Paré D. 2010. Carbon accumulation in agricultural soils after afforestation: a meta-analysis. Global Change Biology, 16: 439-453.

Laik R, Kumar K, Das D K, et al. 2009. Labile soil organic matter pools in a calciorthent after 18 years of afforestation by different plantations. Applied Soil Ecology, 42: 71-78.

Li C J, Li Y, Ma J, et al. 2010. Spatial heterogeneity of soil chemical properties between Haloxylon persicum and Haloxylon ammodendron populations. Journal of Arid Land, 2(4): 257-265.

Li X D, Wei L, Zhang Y C, et al. 2009. Effects of land use regimes on soil physical and chemical properties in the Longzhong part of Loess Plateau. Acta Prataculturae Sinica, 18(4): 103-110.

Li Y M, Cao G M, Wang Y S. 2006. Effects of reclamation on soil organic carbon in Haibei alpine meadow. Chinese Journal of Ecology, 25(8): 911-915.

Liu C, Ren Y L, He J S. 2009. Soil dissolved organic carbon decreased following 40-year grassland afforestation. Acta Scientiarum Naturalium Universitatis Pekinensis, 45(3): 511-518.

Liu H L, Zhang W H, Wang K. 2009. Effect of reclamation on soil properties of zonal and intrazonal grasslands in agro-pastoral ecotone. Transactions of the Chinese Society of Agricultural Engineering, 25(10): 272-277.

Liu M Y, Chang Q R, Qi Y B, et al. 2010. Soil organic carbon and particulate organic carbon under different land use types on the Loess Plateau. Journal of Natural Resources, 25(2): 218-226.

Luo G P, Xu W Q, Chen X. 2005. Effect of different land-use systems on soil properties in the alluvial plain-oasis in the arid land. Acta Geographica Sinica, 60(5): 779-790.

Lützow M V, Kögel-Knabner I, Ekschmitt K, et al. 2006. Stabilization of organic matter in temperate soils: mechanisms and their relevance under different soil conditions-a review. European Journal of Soil Science, 57: 426-445.

Morari F, Lugato E, Berti A, et al. 2006. Long-term effects of recommended management practices on soil carbon changes and sequestration in northeastern Italy. Soil Use and Management, 22: 71-81.

Nelson D W, Sommers L E. 1982. Total carbon, organic carbon, and organic matter. In: Page A L, Miller R H, Keeney D R. Methods of
Soil Analysis, Agronomy, part 2. $2^{\text {nd }}$ ed. Madison, WI: ASA and SSSA, 539-577.

Paul K I, Polglase P J, Nyakuengama J G, et al. 2002. Change in soil carbon following afforestation. Forest Ecology and Management, 168 (1-3): 241-257.

Poeplau C, Don A, Vesterdal L, et al. 2011. Temporal dynamics of soil organic carbon after land-use change in the temperate zone-carbon response functions as a model approach. Global Change Biology, 17: 2415-2427.

Purakayastha T J, Chhonkar P K, Bhadraray S, et al. 2007. Long-term effects of different land use and soil management on various organic carbon fractions in Inceptsol of subtropical India. Australian Journal of Soil Research, 45(1): 33-40.

Raiesi F. 2012a. Soil properties and C dynamics in abandoned and cultivated farmlands in a semi-arid ecosystem. Plant and Soil, 351: $161-175$.

Raiesi F. 2012b. Land abandonment effect on $\mathrm{N}$ mineralization and microbial biomass $\mathrm{N}$ in a semi-arid calcareous soil from Iran. Journal of Arid Environments, 76: 80-87.

Rong L, Li S J, Li X W, et al. 2011. Carbon dynamics of fine root (grass root) decomposition and active soil organic carbon in various models of land use conversion from agricultural lands into forest lands. Acta Ecologica Sinica, 31(1): 137-144.

Su Y Z, Liu W J, Yang R, et al. 2009. Carbon sequestration effect following retirement of degraded croplands into alfalfa forage land in the middle of Hexi Corridor region, Northwest China. Acta ecologica sinica, 29(12): 6385-6391.

Tang G Y, Li K, Sun Y Y, et al. 2010. Soil labile organic carbon contents and their allocation characteristics under different land uses at dry-hot valley. Environmental Science, 31(5): 1365-1371.

Wang B, Liu G B, Xue S, et al. 2011. Changes in soil physico-chemical and microbiological properties during natural succession on abandoned farmland in the Loess Plateau. Environmental Earth Sciences, 62: 915-925.

Wang F, Xiao H L, Su Y Z, et al. 2011. Changes of soil quality after reclamation in oasis saline meadow in Linze, Gansu, China. Journal of Desert Research, 31(3): 723-728.

Wang L L, Song C C, Ge R J, et al. 2009. Soil organic carbon storage under different land-use types in Sanjiang Plain. China Environmental Science, 29(6): 656-660.

Wang X L, Guo S L, Ma Y H, et al. 2007. Effects of land use type on soil organic $\mathrm{C}$ and total $\mathrm{N}$ in a small watershed in loess hilly-gully region. Chinese Journal of Applied Ecology, 18(6): 1281-1285.

Wei J, Liu W G, Cheng J M, et al. 2011. Dynamics of soil organic carbon storage following restoration of grassland on Yunwu Mountain. Acta Ecologica Sinica, 31: 271-275.

Wu H B, Guo Z T, Peng C H. 2003. Land use induced changes of organic 
carbon storage in soils of China. Global Change Biology, 9: 305-315.

Wu J G, Zhang X Q, Xu D Y. 2004. Changes in soil labile organic carbon under different land use in the Liupan mountain forest zone. Acta Phytoecologica Sinica, 28(5): 657-664.

Xu M G, Yu R, Sun X F, et al. 2006. Effects of long-term fertilization on labile organic matter and carbon management index (CMI) of the typical soils of China. Plant Nutrition and Fertilizer Science, 12(4): 459-465.

Yang W Z, Shao M A. 2000. Research on Soil Water Content at the Loess Plateau. Beijing: Science Press, 4-11.

Yang Y S, Xie J S, Sheng H, et al. 2009. The impact of land use/cover change on soil organic carbon stocks and quality in mid-subtropical mountainous area of southern China. Journal of Geographical Sciences, 19: 49-57.
Zhang E H, Huang G B. 2002. Limited factors and solutions of agricultural sustainable development in Loess Plateau of Gansu province. Journal of Soil and Water Conservation, 16(5): 9-13.

Zhang J H, Li G D, Nan Z R, et al. 2009. Temporal and spatial distribution of soil organic carbon under different land uses in the middle reaches of Heihe River. Journal of Lanzhou University: Natural Sciences, 48(4): 66-73.

Zhu B B, Li Z B, Li P, et al. 2010. Soil erodibility, microbial biomass, and physical-chemical property changes during long-term natural vegetation restoration: a case study in the Loess Plateau, China. Ecological Research, 25: 531-541.

Zhu Z J, Jiang P K, Xu Q F. 2006. Study on the active organic carbon in soil under different types of vegetation. Forest Research, 19(4): 523-526. 